\title{
NESTMATE COPULATION IN THE NEOTROPICAL EUSOCIAL WASP POLISTES INSTABILIS DE SAUSSURE (HYMENOPTERA: VESPIDAE)
}

\author{
By SEAN O'DonNell \\ Department of Entomology \\ University of California \\ Davis, CA 95616
}

\begin{abstract}
Copulation between individually marked nestmates of the Neotropical eusocial wasp Polistes instabilis is reported. Polistes copulations are rarely observed in the field; this observation is the first documented case of nestmate copulation in the genus. Hamilton (1964) predicted high rates of nestmate copulation for tropical Polistes populations which have asynchronous colony cycles relative to temperate populations. Nestmate copulation may lead to relatively high levels of inbreeding in tropical Polistes species.
\end{abstract}

\section{INTRODUCTION}

Relative to temperate congeners, populations of tropical Polistes species are asynchronous in colony foundation and reproduction (West Eberhard 1969; Richards 1978; Young 1986). Even in seasonal tropical habitats, Polistes colonies can be found simultaneously in different stages of development (S. O'D. pers. obs.). Hamilton (1964) predicted that copulation among nestmates will be most common in tropical Polistes species because when reproductives emerge asynchronously from different colonies, the availability of non-nestmate mating partners is reduced. Polistes nestmates tend to be close genetic relatives (reviewed in Reeve 1991); therefore, rates of inbreeding should be higher in tropical than in temperate Polistes species if nestmate copulations are frequent. These predictions remain largely untested.

Here I report copulation between individually marked nestmates of the Neotropical eusocial wasp Polistes instabilis. Polistes copulations are rarely observed in the field (West Eberhard 1969;

Manuscript received 21 December 1993. 
Noonan 1978; Hook 1982), and copulation between identified nestmates has not previously been reported. This observation of nestmate copulation lends behavioral support to Hamilton's (1964) predictions, and is significant because little time has been devoted to the study of tropical Polistes species (Reeve 1991).

\section{METHODS}

The copulation occurred in a $P$. instabilis colony in which adult wasps were being observed as part of a study of division of labor. The colony was located at Centro Ecologico la Pacífica in Guanacaste Province, Costa Rica. From 24 to 26 August 1988 all adult wasps in the colony (one queen, 11 other females) were marked. Additional adults (11 females, 12 males) were marked in the evening of days on which they emerged.

Observations were made daily from 27 August to 6 September for periods of 2 to $4 \mathrm{~h}$ per day (38:45 h total); several surveys of nest occupants were made on 7 and 8 September. On some days experimental worker removals were performed; periods between these manipulations are referred to as control observations. During all observation periods, scan samples of wasps on the nest and their behavior were made every $5 \mathrm{~min}$ and all occurrences of forager arrivals were noted.

\section{RESULTS}

The queen (wasp number 22) was seen laying eggs on all observation days except 31 August, 1 September, and 6 September; no other female was observed attempting to oviposit. No evidence of queen conflict with other females (e.g., dominance interactions) was noted. The queen spent time away from the nest on every observation day, but her activities while away from the nest are unknown. Behavior of the queen changed dramatically three days before the observed copulation. From 27 August to 4 September, the queen was on the nest for $81.9 \%$ of 393 scan samples (70 to $100 \%$ of scans per day). On 5 September the queen was present for only $39.6 \%$ of 48 scans, and on 6 September for none of 24 scans.

From 5 September onward, the female later seen in copula (number 15) was frequently on the nest and was aggressive toward nestmates, exhibiting the highest rate of dominance behavior $(5.6 \%$ of scans when present) in the colony. Number 15 was an active 
forager, ranking fourth highest among 22 workers in rate of nectar foraging ( 0.45 trips/hour during control periods).

On 8 September a male which had emerged and was marked the previous day (number 115) was observed copulating with number 15 on the face of the nest while the queen was absent. The male was positioned standing on the female's back; the female's gaster was bent upwards at the tip with the sting chamber open and in contact with the male's exerted genitalia. Number 15 did not appear to struggle or attempt to move away. Genital contact was broken when I approached the nest closely, but the male remained atop the female and both engaged in a raised-wing threat display. Three other females and one other male were present on the nest during the copulation. The nest was predated on 9 September, possibly by a white-throated magpie-jay (Calocitta formosa), and all wasps were lost.

\section{Discussion}

The behavior of wasp number 15 is similar to that described by Hughes \& Strassmann (1988) for workers superseding $P$. instabilis queens: dominant, actively foraging workers were most likely to replace experimentally removed queens. Similarly, a positive relationship between dominance, rate of foraging, and likelihood of superseding the queen has been documented in P. exclamans workers (Strassmann \& Meyer 1983).

In temperate Polistes species, males produced early in colony development copulate primarily with virgin workers and earlyseason reproductives (gynes) in other colonies (Strassmann \& Meyer 1983; Kasuya 1983; Page et al. 1989). Copulation on Polistes nests has been recorded in tropical species $(P$. erythrocephalus in Colombia, West Eberhard 1969; P. tepidus in Australia, Hook 1982), but in these cases the wasps were not marked and may not have been nestmates.

The nestmate copulation observed in $P$. instabilis suggests that males play a role in inseminating related females in this species. This observation lends behavioral support to Hamilton's (1964) suggestion that inbreeding may be more prevalent in tropical Polistes populations with asynchronous reproduction than in temperate populations. Long-term observations of marked individuals, combined with genetic studies that provide measures of inbreeding 
(Metcalf 1980; Davis et al. 1990), are needed to assess the frequency of mating among close relatives in tropical Polistes species.

\section{ACKNOWLEDGEMENTS}

Thanks to Werner and Lilly Hagnauer for permission to work on their property. Susan Bulova and an anonymous reviewer made helpful comments on the manuscript. Financial support was provided by NSF grant BNS-8517519 (Robert Jeanne, P.I.) and by a postdoctoral fellowship from the NSF funded Animal Behavior Research Training Grant at the University of California at Davis.

\section{Literature Cited}

Davis, S. K.; Strassmann, J. E.; Hughes, C.; Pletscher, S.; and Templeton, A. R. 1990. Population structure and kinship in Polistes (Hymenoptera: Vespidae): an analysis using ribosomal DNA and protein electrophoresis. Evolution 44: $1242-1253$.

Hamilton, W. D. 1964. The genetical evolution of social behavior. II. Journal of Theoretical Biology 7: 17-52.

Hook, A. W. 1982. Observations on a declining nest of Polistes tepidus (F.) (Hymenoptera: Vespidae). Journal of the Australian Entomological Society 21: 277-278.

Hughes, C. R. and J. E. Strassmann. 1988. Age is more important than size in determining dominance among workers in the primitively eusocial wasp, Polistes instabilis. Behaviour 107: 1-14.

Kasuya, E. 1983. Social behavior of early emerging males of a Japanese paper wasp, Polistes chinensis antennalis (Hymenoptera: Vespidae). Research in Population Ecology 25: 143-149.

Metcalf, R. A. 1980. Sex ratios, parent-offspring conflict, and local competition for mates in the social wasps Polistes metricus and Polistes variatus. The American Naturalist 116: 642-654.

Noonan, K. M. 1978. Sex ratio of parental investment in colonies of the social wasp Polistes fuscatus. Science 199: 1354-1356.

Page, R. E.; Post, D. C.; and Metcalf, R. A. 1989. Satellite nests, early males, and plasticity of reproductive behavior in a paper wasp. The American Naturalist 119: 263-281.

Reeve, H. K. 1991. Polistes. In K. G. Ross \& R. W. Matthews (eds) The social biology of wasps. Cornell University Press, Ithaca, NY. pp. 99-148.

Richards, O. W. 1978. The social wasps of the Americas. British Museum (Natural History), London.

Strassmann, J. E., and Meyer, D. C. 1983. Gerontocracy in the social wasp, Polistes exclamans. Animal Behaviour 31: 431-438.

West Eberhard, M. J. 1969. The social biology of polistine wasps. Miscellaneous Publications of the Museum of Zoology, University of Michigan 140: 1-101.

Young, A. M. 1986. Natural history notes on the social paper wasp Polistes erythrocephalus Latreille (Hymenoptera, Vespidae, Polistinae) in Costa Rica. Journal of the Kansas Entomological Society 59: 712-722. 

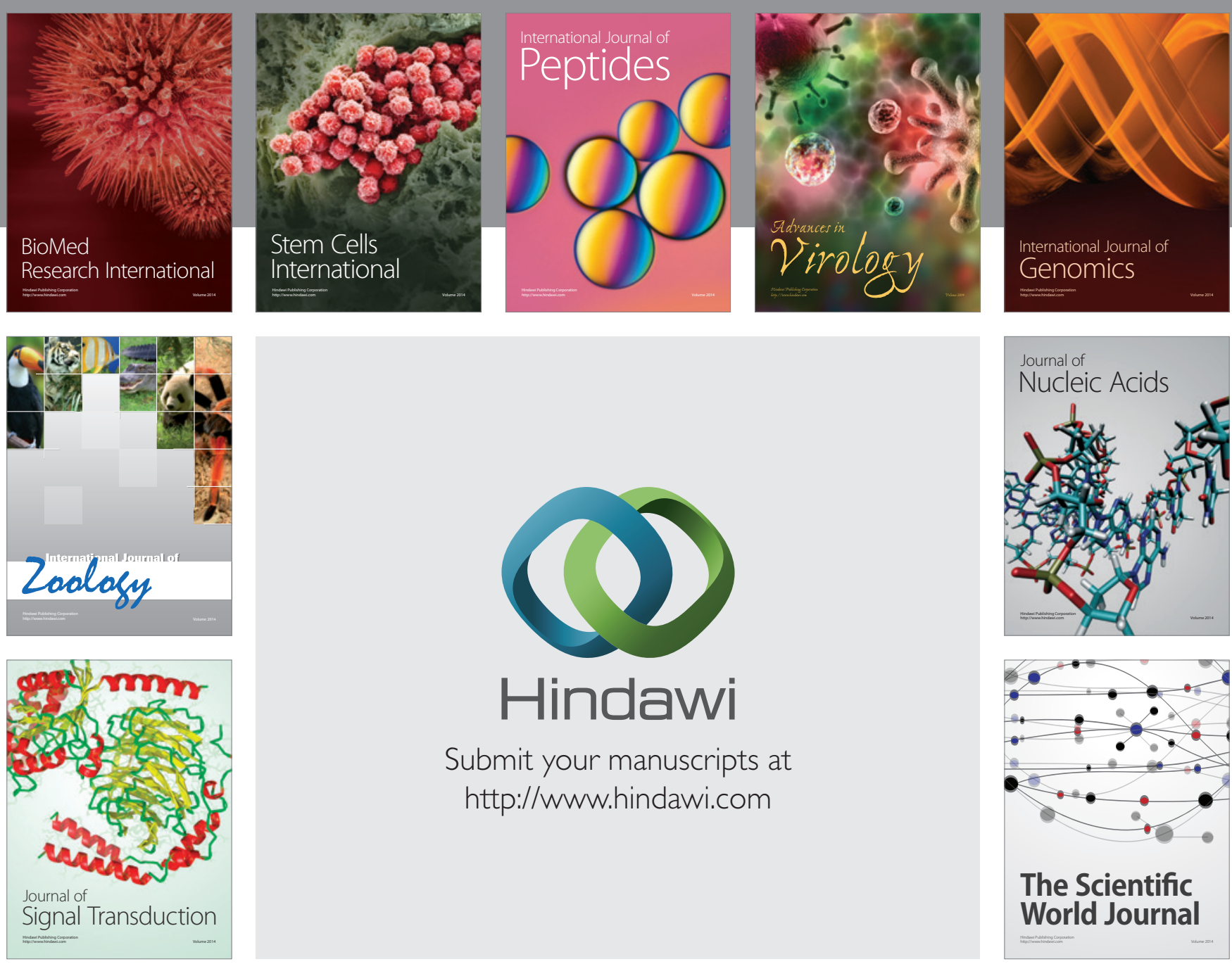

Submit your manuscripts at

http://www.hindawi.com
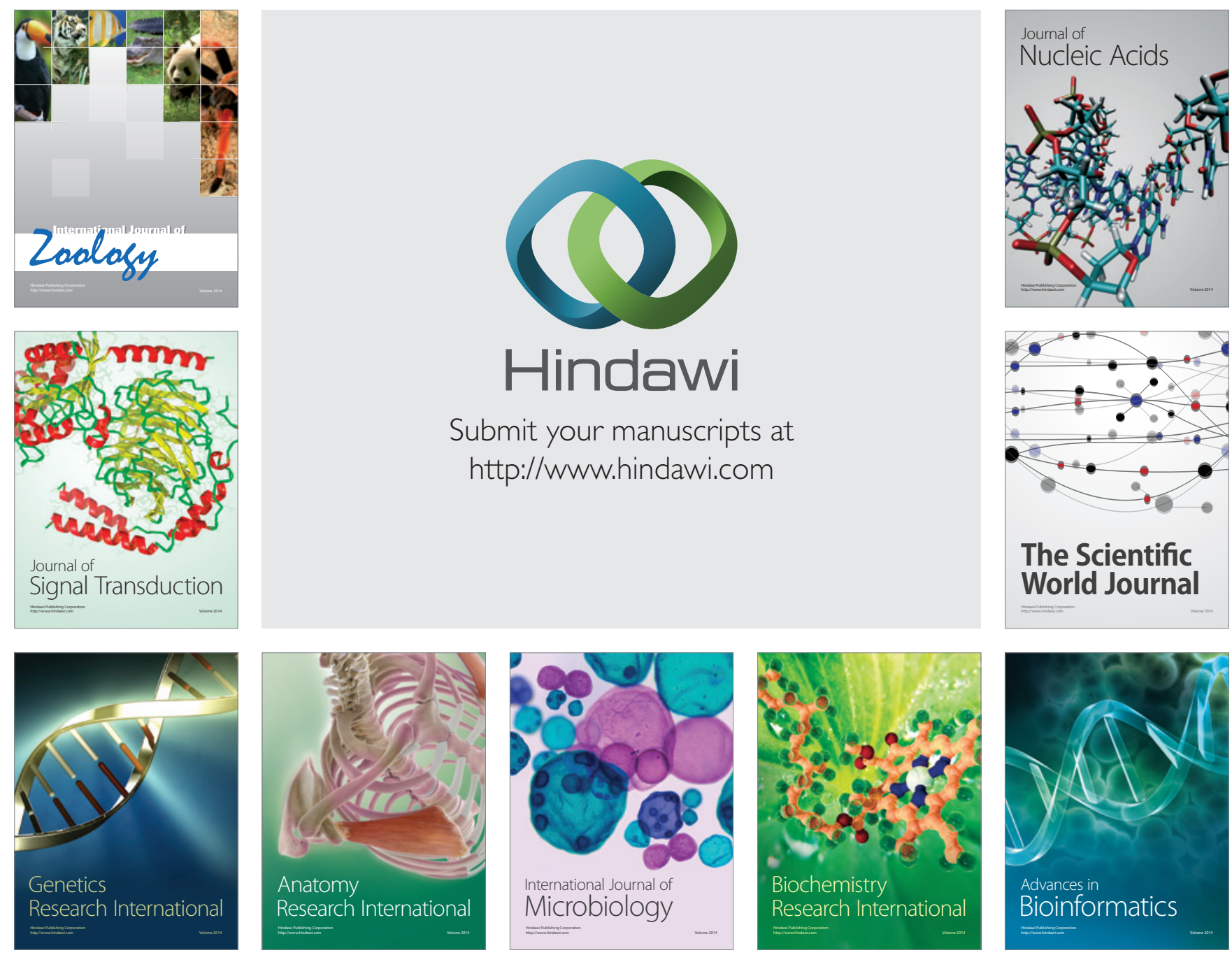

The Scientific World Journal
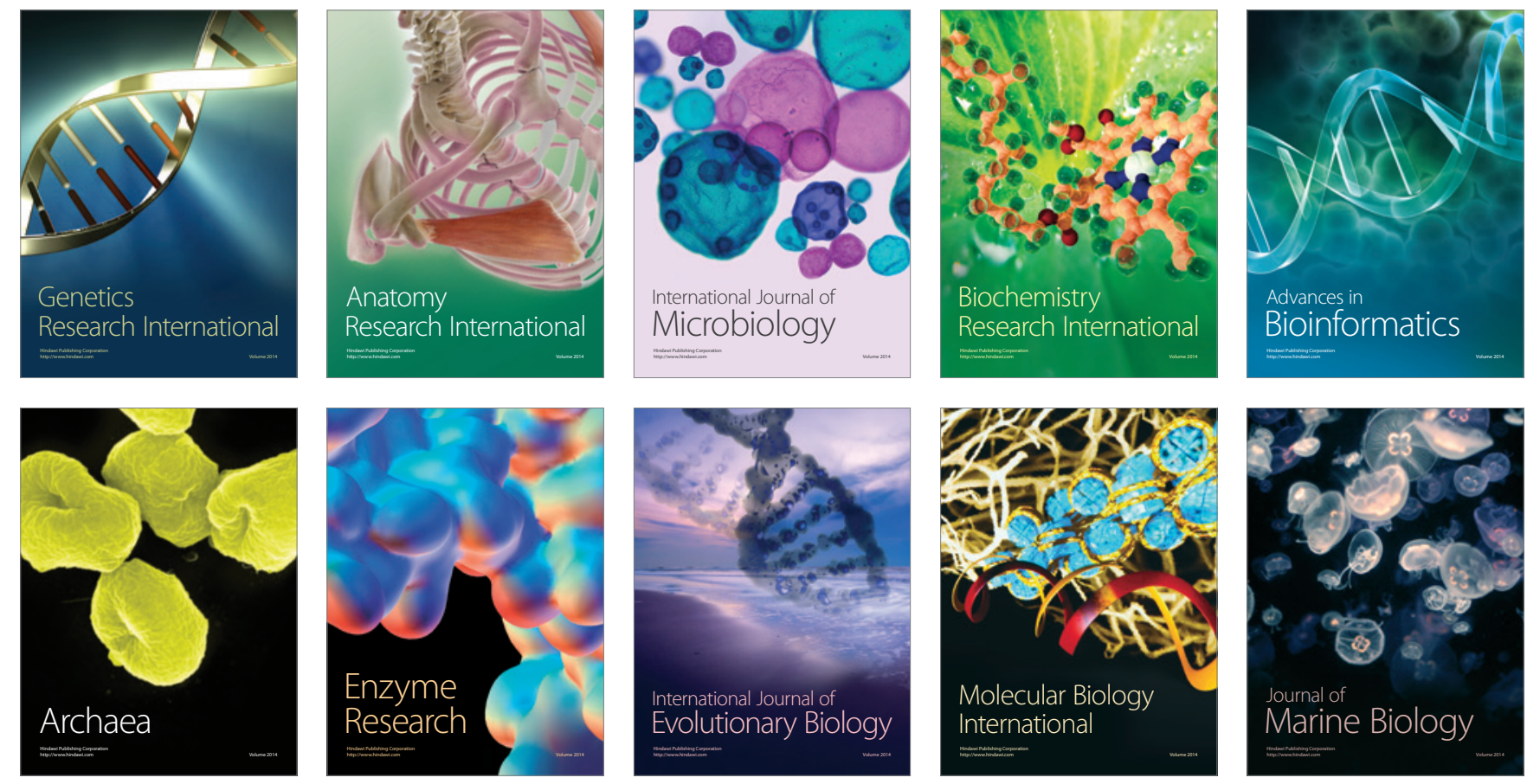